\title{
Risk factors of permanent hypoparathyroidism after total thyroidectomy and central neck dissection for papillary thyroid cancer: a prospective study
}

\author{
Paulina Godlewska ${ }^{1}$, Małgorzata Benke ${ }^{1}$, Elżbieta Stachlewska-Nasfeter ${ }^{1}$, Jacek Gałczyński ${ }^{1}$, \\ Bartosz Puła', Marek Dedecjus ${ }^{1}$ \\ ${ }^{1}$ Department of Endocrine Oncology and Nuclear Medicine, Maria Skłodowska-Curie National Institute of Oncology \\ - National Research Institute, Warsaw, Poland \\ ${ }^{2}$ Department of Haematology, Institute of Haematology and Transfusion Medicine, Warsaw, Poland
}

\begin{abstract}
Introduction: Inadvertent removal of, or damage to the parathyroid glands in the course of operations on the anterior neck compartment are responsible for over $80 \%$ of cases of chronic hypoparathyroidism (HypoPT). This study searched for factors related to the development of permanent HypoPT after total thyroidectomy and central neck lymphadenectomy in patients with thyroid carcinoma.

Material and methods: In total, 89 of 103 screened patients met the study's criteria and were put under prospective one-year observation. Demographic and surgical factors as well as the biochemical parameters of mineral homeostasis, controlled both preoperatively and postoperatively, were subject to statistical analysis. In line with contemporary guidelines, postoperative hypocalcaemia, rather than an abnormally low serum parathormone (PTH) concentration, was considered a diagnostic criterion of HypoPT.

Results: On postoperative day one (POD1), serum concentration of PTH decreased below the normal range $(<12$ pg/mL) in 29 patients and was undetectable in 19 patients $(<6 \mathrm{pg} / \mathrm{mL})$. At one year postoperatively, 12 patients with undetectable POD1 PTH required treatment for hypocalcaemia and were diagnosed with permanent hypoPT. All the other patients regained normocalcaemia. Relative risk of permanent HypoPT associated with undetectable POD1 PTH was 88.75. A significant difference in median POD1 serum calcium concentration between the patients with undetectable POD1 PTH and those with detectable POD1 PTH was found ( $p<0.001)$. The difference between the POD1 serum calcium in patients with permanent or transient HypoPT in the subgroup with undetectable POD1 PTH did not reach the level of statistical significance (median, $1.82 \mathrm{mmol} / \mathrm{L} v s .1 .96 \mathrm{mmol} / \mathrm{L}$ ). At one month postoperatively, in patients who later developed permanent HypoPT, serum calcium was lower than it was in all other patients $(p=0.167)$. At one year postoperatively, serum concentration of PTH was in the normal range in 10 of 12 patients with permanent HypoPT; however, it was significantly lower than it had been before the operation and distinctly lower than it was in patients who regained normocalcaemia. The number of parathyroid glands either dissected or autotransplanted did not affect the development of permanent HypoPT.

Conclusions: Undetectable POD1 PTH is an important risk factor of permanent HypoPT. The main cause of permanent HypoPT was irreversible damage to the left in situ parathyroid glands. (Endokrynol Pol 2020; 71 (2): 126-133)
\end{abstract}

Key words: parathyroid hormone; hypoparathyroidism; thyroidectomy; hypocalcaemia; thyroid carcinoma

\section{Introduction}

Anatomical relations and common blood supply make parathyroid glands vulnerable to damage in the course of total thyroidectomy. Parathyroid hormone enhances calcium reabsorption in the kidney and activates vita$\min 1.25(\mathrm{OH}) 2 \mathrm{D} 3$ synthesis, which increases intestinal absorption of calcium and phosphate, and directly stimulates the release of calcium and phosphate from bone [1]. The promotion of renal phosphate excretion provides protection from renal and other soft tissue calcifications as well as bone mineralisation disturbances, which result from hyperphosphataemia $[2,3]$. The physiological, intermittent secretion of parathormone (PTH) has a stimulatory effect on bone formation and indirectly enhances bone resorption, which prevents bone ageing and brittleness [4]. While hypocalcaemia alone may be satisfactorily managed with the use of calcium supplements and active vitamin D metabolites, standard treatment of hypoparathyroidism (HypoPT) cannot fully replace the multidirectional activity of PTH. Therefore, chronic HypoPT has a negative impact on quality of life $[3,5,6]$.

Postsurgical hypofunction of the parathyroid glands is the most prevalent aetiology of HypoPT [2]. The time between transient and permanent HypoPT is usually 6-12 months postoperatively $[2,7,8]$. Some authors have diagnosed protracted HypoPT in patients who require treatment for hypocalcaemia at 4-6 weeks postoperatively $[9,10]$. According to the European So- 
ciety of Endocrinology's (ESE) recent guidelines on the treatment of chronic HypoPT in adults, in the presence of hypocalcaemia a specific cut-off limit for serum PTH concentration cannot be defined because hypocalcaemia should normally induce a marked increase in PTH secretion [7]. However other causes of hypocalcaemia, such as hungry bone syndrome, secondary hyperparathyroidism, or chronic hypomagnesaemia should be considered.

The issue of risk factors of permanent HypoPT is underrepresented in the current medical literature; this is primarily because health care in the perioperative period is divided between surgeons, endocrinologists, and family doctors, working separately. The risk of permanent HypoPT is increased with total vs. subtotal thyroidectomy, completion thyroidectomy, reoperations for bleeding, and central node dissection [11-13]. The aim of this prospective observational study was to determine factors that are related to the development of permanent HypoPT in patients who are diagnosed with papillary carcinoma of the thyroid and are undergoing total thyroidectomy with central lymph node dissection. An understanding of factors that herald permanent hypocalcaemia would provide surgeons with early information on postoperative outcomes and allow the personalisation of postoperative treatments.

\section{Material and methods}

In this study 103 patients who were scheduled for surgical treatment in our department between 2014 and 2016 and who were willing to attend regular medical appointments were screened for participation. All patients were diagnosed with papillary thyroid carcinoma based on a fine needle aspiration biopsy. Inclusion criteria included the following: normal biochemical results of calcium metabolism, normal serum albumin and total protein, normal thyroid, liver, and kidney function, and normal 24-hour urine calcium excretion. Cases of completion thyroidectomy and patients with diseases or who were taking medications that affect calcium homeostasis were excluded. Vitamin D deficiency was not an exclusion criterion unless it was accompanied by secondary hyperparathyroidism. The study received local ethical board approval, and each participant received and signed an informed consent form.

Total extracapsular excision of the thyroid gland with lymphadenectomy of the central neck compartment was performed on each patient by the same team of surgeons. At least two parathyroids were visualised intraoperatively. In each case the thyroid was devascularised by selective closure of distal branches of the thyroid arteries to spare the vascular supply of the parathyroids.

Biochemical monitoring of mineral homeostasis included the following: serum calcium (Calcium Arsenazo III, Beckman Coulter, Inc., normal range: $2.2-2.65 \mathrm{mmol} / \mathrm{L}$ ) phosphate (Inorganic Phosphorous, Beckman Coulter, Inc., normal range: $0.81-1.45 \mathrm{mmol} / \mathrm{L}$ ), magnesium (Magnesium, Beckman Coulter, Inc., normal range: 0.77-1.06 mmol/L), PTH (Access Intact PTH Assay, Beckman Coulter, Inc., normal range: $12-88 \mathrm{pg} / \mathrm{mL}$ ), and 25-hydroxy vitamin D3 (Elecsys2010 Vitamin Total II, Cobas e, Roche Diagnostics GmbH, normal range: $>20 \mathrm{mg} / \mathrm{mL}$ ). A decrease in serum albumin concentration by $1 \mathrm{~g} / \mathrm{dL}$ leads to a drop in the total serum calcium concentration by $0.2 \mathrm{mmol} / \mathrm{L}$. In line with the inclusion criteria, the serum albumin was normal in all participants. In the early postoperative period, patients with biochemical hypocalcaemia - which was defined as a serum calcium concentration below $2 \mathrm{mmol} / \mathrm{L}$ - as well as symptomatic hypocalcaemia - which was understood as symptoms associated with serum calcium decrease - were given calcium carbonate, magnesium lactate, and alphacalcidol orally, as well as calcium gluconate intravenously, when needed.

The abovementioned laboratory tests were performed one week prior to surgery, on admission, and daily, starting from postoperative day one (POD1) (serum calcium, magnesium, PTH) until discharge from the hospital. Thereafter, the tests were repeated after 7-14 days and in 4-5-week intervals until both active vitamin $D$ and calcium could be discontinued. All patients were followed-up by the same endocrinologist throughout the study. The final statistical analysis was based on the results that were obtained one year postoperatively. Patients with normal or elevated serum phosphate and normal magnesium concentrations, who required treatment for hypocalcaemia, were diagnosed with permanent HypoPT.

The numbers of parathyroids that were transplanted into the sternocleidomastoid muscle as well as of those found in pathological material were recorded. Pathological staging was based on the tumour/nodes/metastases (TNM) system.

The results were subject to statistical analysis using the R software version 3.5.4 (http://cran.r-project.org). The U-Mann-Whitney test was used to compare two variables of non-parametric distribution, while the Kruskal-Wallis test and Dunn's multiple comparison test were both used to assess the significance of differences between three or more groups. The Wilcoxon signed-rank test was used to compare related samples and repeated measurements. Finally, the correlation between qualitative variables was assessed with Fisher's exact test. Statistical significance was set at $0.05(\mathrm{p}<0.05)$.

\section{Results}

Of 103 screened patients, 89 ( 69 women and 20 men) aged $23-80$ years (mean 46.6 ; median 42 ) met the study's criteria. Their serum PTH concentration ranged from 20 to $74 \mathrm{pg} / \mathrm{mL}$, mean $43.2 \mathrm{pg} / \mathrm{mL}$, median $42 \mathrm{pg} / \mathrm{mL}$. The serum PTH showed a significant, positive correlation with the age of the patients $(\mathrm{p}=0.0034$, Pearson's $r=0.3)$ and was negatively correlated with serum calcium $(\mathrm{p}=0.04$, Spearman $\mathrm{R}=-0.22)$. A negative correlation between PTH and 25-hydroxy vitamin D3 did not reach statistical significance $(p=0.164$, Spearman's $R=-0.15)$. In addition, no significant difference between serum PTH for 25-hydroxy vitamin D3 higher or lower than $20 \mathrm{ng} / \mathrm{mL}(\mathrm{p}=0.11$ ) was found.

Significant decreases in serum calcium, magnesium, and PTH concentrations were observed on POD1 in the entire patient group $(p<0.0001)$. Serum calcium and magnesium were positively correlated with PTH $(p<0.0001$, Spearman's $R=0.5 ; p=0.006$, Spearman's $R=0.4$, respectively), and serum calcium was positively correlated with magnesium ( $\mathrm{p}=0.005$, Spearman's $R=0.4$ ). With therapy initiated on POD1 in cases of hypocalcaemia, a gradual increase in serum calcium was noted over the two subsequent days, but serum magnesium continued to decrease. No difference in POD1 serum calcium between patients with normal serum 25-hydroxy-vitamin D3 and vitamin D3 deficiency was observed $(\mathrm{p}=0.8)$. 
On POD1, the serum PTH concentration dropped below the normal range (POD1 PTH $<12 \mathrm{pg} / \mathrm{mL}$ ) in 29 patients, whereas it was undetectable (POD1 PTH $<6$ $\mathrm{pg} / \mathrm{mL}$ ) in 19 patients. Biochemical hypocalcaemia in the early postoperative period, which occurred in 43 (48.3\%) patients, was related to the absolute POD1 PTH concentration and the percentage decrease in serum PTH ( $p<0.0001)$. The number of parathyroids that were found in the pathologic specimen, the tumour burden (pT1-2 vs. pT3-4), and age did not differ significantly between the patients with biochemical hypocalcaemia and those with a higher serum calcium $(\mathrm{p}=0.085, \mathrm{p}=0.43, \mathrm{p}=0.37$, respectively).

One year after surgery, $12(13.6 \%)$ patients required treatment for hypocalcaemia and were diagnosed with permanent HypoPT. At one year after the surgery, their median serum calcium concentration while on treatment was $2.08 \mathrm{mmol} / \mathrm{L}(1.99-2.2 \mathrm{mmol} / \mathrm{L})$. Daily doses of alphacalcidol ranged from 0.25 to $2 \mathrm{mcg}$, and calcium carbonate ranged from 1 to $3 \mathrm{~g}$. The basal characteristics of patients with permanent hypocalcaemia are presented in Table 1.

We found that PTH was undetectable on POD1 in all patients with permanent HypoPT. Seven other patients with undetectable POD1 PTH as well as all the patients with detectable POD1 PTH did not require treatment for hypocalcaemia one year postoperatively.

The relative risk (RR) of permanent HypoPT in cases of POD1 PTH of $<6 \mathrm{pg} / \mathrm{mL}$ was 88.75 [95\% confidence interval (CI): 5.49-1434.67; $p=0.0016]$. The 95\% CI range was wide because there were no cases of permanent HypoPT among patients with a POD1 PTH $\geq 6$ pg/mL, and the group with undetectable POD1 PTH was small.
The Kruskal-Wallis test was used to compare clinical, surgical, and pre- and postoperative biochemical parameters in three groups of patients: those with permanent HypoPT, patients with an undetectable POD1 PTH concentration who recovered from hypocalcaemia, and patients with a POD1 PTH concentration of $\geq 6$ $\mathrm{pg} / \mathrm{mL}$. The results are shown in Table 2 .

All of the patients with an undetectable POD1 PTH concentration had serum calcium concentration on POD1 that was significantly lower than in patients with a higher POD1 PTH concentration (median: 1.82 vs. 1.96 , vs. $2.07 \mathrm{mmol} / \mathrm{L} ; \mathrm{p}<0.001$ ). The difference in serum POD1 calcium concentration between the patients who later developed permanent HypoPT and those who regained normocalcaemia despite an undetectable POD1 PTH concentration did not reach statistical significance, which may have been due to the small size of both subgroups (Fig. 1).

On POD1, the median serum magnesium concentration was the lowest in patients who developed permanent HypoPT and the highest in patients with detectable POD1 PTH, but its absolute concentration, or the incidence of hypomagnesaemia, would not allow the prediction of permanent hypocalcaemia.

One month postoperatively, serum calcium concentrations were lower in patients who developed permanent HypoPT than in all the patients who did not. However, the difference once again did not reach the level of statistical significance (median: 2.18 vs. 2.36 vs. $2.36 \mathrm{mmol} / \mathrm{L}, \mathrm{p}=0.167$ ). The patient groups were too small to draw conclusions regarding the threshold of serum calcium concentration that would be predictive of permanent hypocalcaemia.

Table 1. Basal descriptive statistics for patients with permanent hypoparathyroidism (HypoPT)

\begin{tabular}{|c|c|c|c|c|c|c|c|c|}
\hline Permanent HypoPT & $\mathbf{n}$ & Mean & SD & Median & 01 & 03 & Min. & Max. \\
\hline Age (years) & 12 & 46.08 & 13.99 & 44.00 & 39.50 & 53.50 & 23.00 & 68.00 \\
\hline $25(\mathrm{OH})$ vitamin D3 preop. & 12 & 21.57 & 11.96 & 20.62 & 14.34 & 23.55 & 8.06 & 51.48 \\
\hline PTH preop. & 12 & 44.67 & 17.52 & 39.00 & 34.50 & 55.25 & 20.00 & 73.00 \\
\hline Ca preop. & 12 & 2.35 & 0.10 & 2.36 & 2.29 & 2.40 & 2.21 & 2.56 \\
\hline Ca POD1 & 12 & 1.84 & 0.16 & 1.82 & 1.78 & 1.94 & 1.56 & 2.11 \\
\hline Ca 1 month & 11 & 2.28 & 0.23 & 2.18 & 2.12 & 2.35 & 2.01 & 2.71 \\
\hline Mg POD1 & 12 & 0.75 & 0.09 & 0.72 & 0.69 & 0.77 & 0.65 & 0.93 \\
\hline Mg POD2 & 9 & 0.68 & 0.06 & 0.70 & 0.67 & 0.71 & 0.57 & 0.77 \\
\hline Lymph nodes dissected (n) & 11 & 6.09 & 6.41 & 4.00 & 2.00 & 6.00 & 1.00 & 22.00 \\
\hline Parathyroids autografted (n) & 12 & 0.08 & 0.29 & 0.00 & 0.00 & 0.00 & 0.00 & 1.00 \\
\hline Parathyroids removed (n) & 12 & 0.33 & 0.49 & 0.00 & 0.00 & 1.00 & 0.00 & 1.00 \\
\hline
\end{tabular}

Reference ranges: Ca — serum total calcium 2.2-2.65 mmol/L; Mg — serum magnesium 0.77-1.06 mmol/L; 25(OH)vitamin D3 > $20 \mathrm{ng} / \mathrm{mL}$; PTH — parathormone 12-88 pg/mL; POD — postoperative day; SD — standard deviation 
Table 2. Comparison of selected variables between patients with permanent hypoparathyroidism (HypoPT), patients with transient HypoPT despite an undetectable postoperative day 1 (POD1) parathormone (PTH), and patients with a measurable PTH concentration on POD1

\begin{tabular}{|c|c|c|c|c|}
\hline \multirow[t]{2}{*}{ Variable } & \multicolumn{2}{|c|}{ Undetectable POD1 PTH } & \multirow{2}{*}{$\begin{array}{c}\text { Measurable P0D1 PTH } \\
\text { Transient HypoPT } \\
\text { or normocalcaemia }(\mathrm{n}=70 \text { ) }\end{array}$} & \multirow[t]{2}{*}{ p } \\
\hline & $\begin{array}{c}\text { Permanent } \\
\text { HypoPT }(\mathrm{n}=12)\end{array}$ & $\begin{array}{c}\text { Transient } \\
\text { HypoPT }(\mathbf{n}=7)\end{array}$ & & \\
\hline Age & $\begin{array}{c}44.00 \\
(39.50 ; 53.50)\end{array}$ & $\begin{array}{c}33.00 \\
(31.50 ; 47.00)\end{array}$ & $\begin{array}{c}42.00 \\
(33.00 ; 64.00)\end{array}$ & 0.476 \\
\hline \multicolumn{5}{|l|}{ Sex } \\
\hline Female & $8(66.7 \%)$ & $6(85.7 \%)$ & $55(78.6 \%)$ & \multirow{2}{*}{0.641} \\
\hline Male & $4(33.3 \%)$ & $1(14.3 \%)$ & $15(21.4 \%)$ & \\
\hline $25(\mathrm{OH})$ vitamin D3 preop. & $\begin{array}{c}20.62 \\
(14.34 ; 23.55) \\
\end{array}$ & $\begin{array}{c}12.01 \\
(10.81 ; 29.91) \\
\end{array}$ & $\begin{array}{c}18.28 \\
(12.70 ; 24.35) \\
\end{array}$ & 0.875 \\
\hline PTH preop. & $\begin{array}{c}39.00 \\
(34.50 ; 55.25)\end{array}$ & $\begin{array}{c}33.00 \\
(26.50 ; 39.50)\end{array}$ & $\begin{array}{c}43.00 \\
(31.00 ; 53.00)\end{array}$ & 0.301 \\
\hline Ca preop. & $2.36(2.29 ; 2.40)$ & $2.46(2.35 ; 2.48)$ & $2.37(2.29 ; 2.44)$ & 0.446 \\
\hline Ca P0D1 & $1.82(1.78 ; 1.94)^{\mathrm{a}}$ & $1.96(1.84 ; 1.97)^{\mathrm{b}}$ & $2.07(1.96 ; 2.15)^{\mathrm{ab}}$ & $<0.001 *$ \\
\hline Ca 1 month & $2.18(2.12 ; 2.35)$ & $2.36(2.16 ; 2.46)$ & $2.36(2.28 ; 2.45)$ & 0.167 \\
\hline Mg POD1 & $0.72(0.69 ; 0.77)$ & $0.73(0.72 ; 0.78)$ & $0.78(0.72 ; 0.82)$ & 0.186 \\
\hline Hyро Mg POD1 & $8(66.7 \%)$ & $5(71.4 \%)$ & $32(46.4 \%)$ & 0.248 \\
\hline Mg POD2 & $0.70(0.67 ; 0.71)$ & $0.74(0.63 ; 0.78)$ & $0.73(0.68 ; 0.81)$ & 0.250 \\
\hline Parathyroids removed (n) & $0.00(0.00 ; 1.00)$ & $0.00(0.00 ; 0.50)$ & $0.00(0.00 ; 1.00)$ & 0.974 \\
\hline Parathyroids autografted (n) & $0.00(0.00 ; 0.00)$ & $0.00(0.00 ; 0.00)$ & $0.00(0.00 ; 0.00)$ & 0.674 \\
\hline Lymph nodes dissected (n) & $4.00(2.00 ; 6.00)$ & $2.00(0.00 ; 3.00)$ & $3.00(1.00 ; 5.75)$ & 0.180 \\
\hline
\end{tabular}

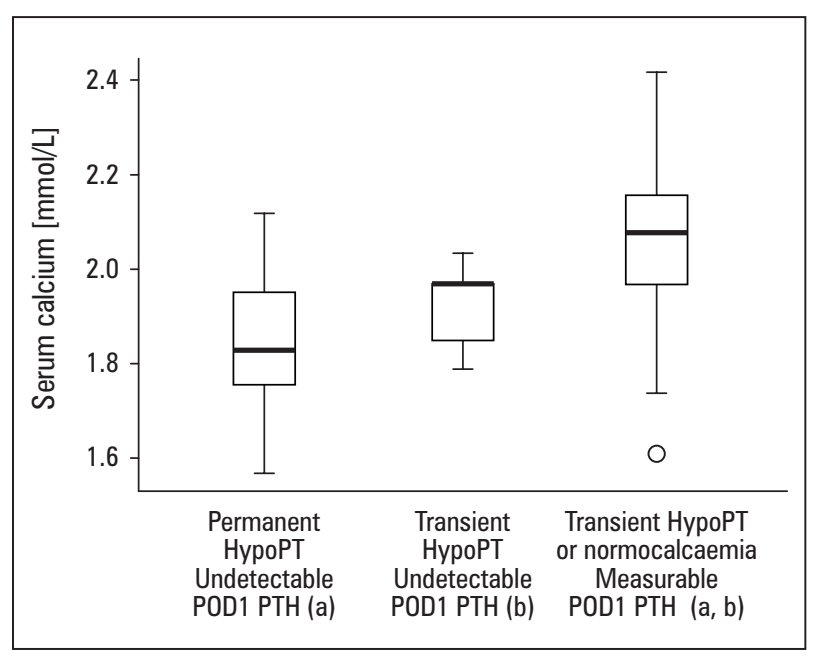

Figure 1. Serum calcium concentration on postoperative day 1 (POD1) in patients with permanent hypoparathyroidism (HypoPT), in patients with transient HypoPT despite an undetectable postoperative day 1 (POD1) parathormone (PTH) concentration, and in patients with a measurable PTH serum concentration on POD1. $a-b$ : differences of statistical significance in post-hoc Dunn's test ( $a$ : $p<0.001, b: p=0.015$ )

Upon pathological examination, a single parathyroid gland had been found in the material from four patients who developed permanent HypoPT, while none was found in the eight other specimens. Autotransplantation of a single parathyroid gland into the muscle had been performed on two patients with undetectable POD1 PTH, and permanent HypoPT developed in one of them. Thus, the number of parathyroid glands that were either removed or transplanted did not affect the long-lasting parathyroid dysfunction in the studied group of patients.

One year postoperatively, in patients with persistent hypocalcaemia the serum PTH concentration was significantly lower than it had been before the operation ( $p=0.003)$; however, it was subnormal in two patients only and normal the other 10 patients (Fig. 2). In the patients who recovered from hypocalcaemia despite an undetectable POD1 PTH concentration, the difference between the serum PTH concentration before and one year after the operation did not reach the level of significance (Tab. 3).

One year after the operation, the serum PTH concentration in patients with permanent HypoPT was significantly lower than it was in all patients who did not require treatment for lasting hypocalcaemia $(\mathrm{p}<0.001)$ and was lower than it was in patients with a POD1 PTH of $<6 \mathrm{pg} / \mathrm{mL}$ who regained normocalcaemia (Tab. 4, Fig. 3). 


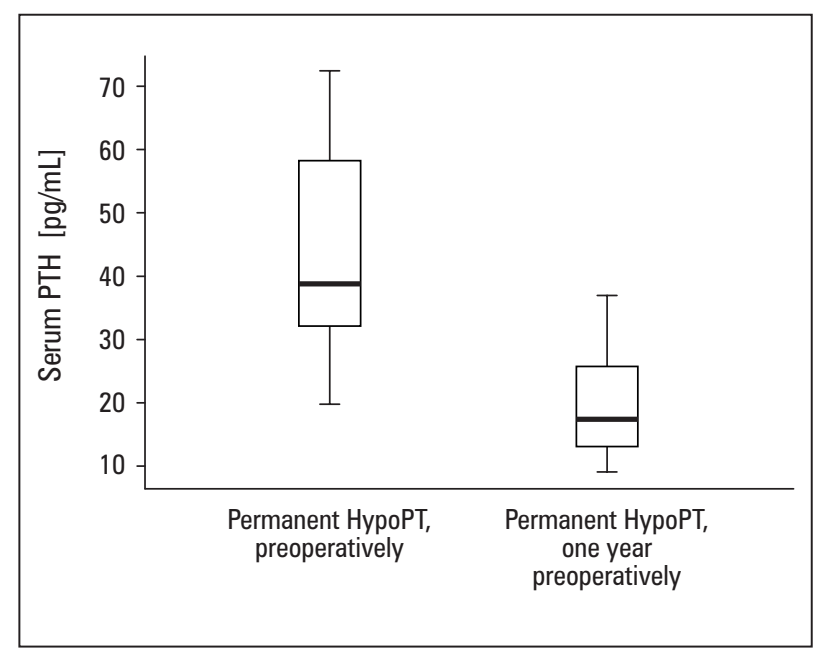

Figure 2. Serum parathormone (PTH) concentration in patients with permanent hypoparathyroidism (HypoPT): preoperatively and at one year postoperatively $(p=0.003)$

\section{Discussion}

The reported prevalence of early postoperative hypocalcaemia ranged from 7.6 to $83 \%$, while permanent HypoPT may complicate 0.5 to $14 \%$ of total thyroidectomies [8-10, 12-14]. Large differences in the rates of early and permanent hypocalcaemia resulted from a lack of uniformly applied criteria for hypocalcaemia and HypoPT as well as from the varying extent of the

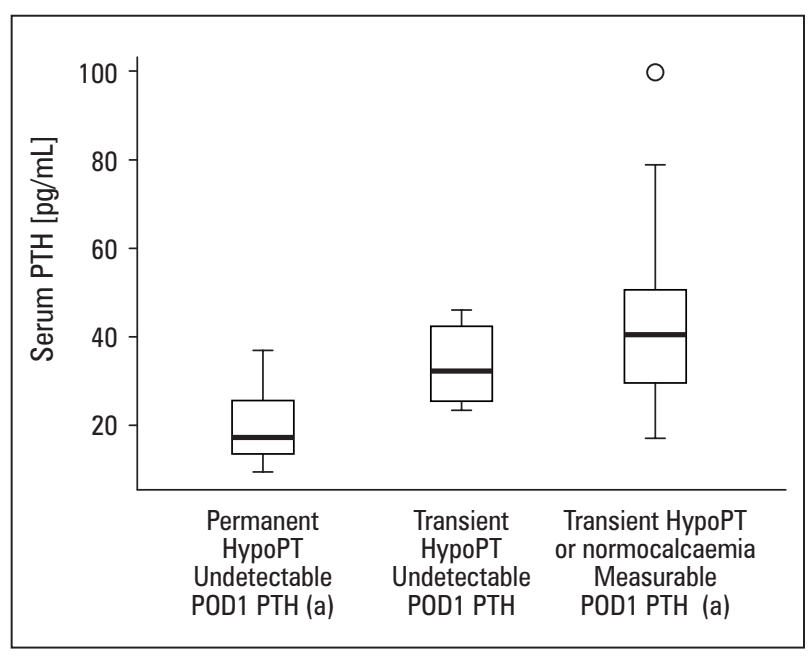

Figure 3. Serum parathormone (PTH) concentration at one year postoperatively: in patients who developed permanent hypocalcaemia, in patients with transient hypoparathyroidism (HypoPT) despite an undetectable postoperative day 1 (POD1) parathormone (PTH) concentration and patients with a measurable POD1 PTH concentration ( $a: p<0.001$ )

operative procedures $[8,10,15,16]$. Many authors have recently defined early postoperative hypocalcaemia as a total serum calcium concentration below $2 \mathrm{mmol} / \mathrm{l}$ or an ionised serum calcium below 1.0-1.05 mmol/L, although these values are lower than the reference ranges $[9,10,16-19]$. The choice of this threshold of

Table 3. Comparison between serum parathormone (PTH) concentration preoperatively and at 1 year postoperatively in patients with permanent hypoparathyroidism (HypoPT), patients with transient HypoPT despite an undetectable postoperative day 1 (POD1) PTH, and patients with a measurable PTH concentration on POD1

\begin{tabular}{lccc}
\hline \multirow{2}{*}{ Serum PTH } & \multicolumn{2}{c}{ Undetectable POD1 PTH } & Measurable POD1 PTH \\
\cline { 2 - 4 } & $\begin{array}{c}\text { Permanent } \\
\text { HypoPT }(\mathbf{n}=\mathbf{1 2})\end{array}$ & $\begin{array}{c}\text { Transient } \\
\text { HypoPT }(\mathbf{n}=\mathbf{6})\end{array}$ & $\begin{array}{c}\text { Transient HypoPT } \\
\text { or normocalcaemia (n }=\mathbf{6 7})\end{array}$ \\
\hline Preoperatively & $39.00(34.50 ; 55.25)$ & $33.00(26.50 ; 39.50)$ & $43.00(31.00 ; 53.00)$ \\
\hline Postoperatively & $17.02(13.34 ; 25.25)$ & $32.00(25.75 ; 40.50)$ & $39.75(29.75 ; 50.25)$ \\
\hline MD $(95 \% \mathrm{Cl})$ & $-21.98(-37.38 ;-13.00)$ & $-1.00(-15.00 ; 7.00)$ & $-3.25(-6.00 ; 1.00)$ \\
\hline $\mathrm{p}$ & $\mathbf{0 . 0 0 3 *}^{*}$ & 0.438 & 0.141 \\
\hline
\end{tabular}

Data are given in median $(01 ; 03)$. Wilcoxon test (paired samples). MD - median difference and its $95 \%$ confidence interval (CI); * $<<0.05$

Table 4. Comparison of serum parathormone (PTH) concentration at 1 year postoperatively between patients with permanent hypoparathyroidism (HypoPT), transient HypoPT despite an undetectable postoperative day 1 (POD1) PTH, and patients with a measurable POD1 PTH concentration

\begin{tabular}{lccc}
\hline & \multicolumn{2}{c}{ Undetectable POD1 PTH } & Measurable POD1 PTH \\
\cline { 2 - 4 } Variable & $\begin{array}{c}\text { Permanent } \\
\text { HypoPT }(\mathbf{n}=\mathbf{1 2})\end{array}$ & $\begin{array}{c}\text { Transient } \\
\text { HypoPT }(\mathbf{n}=\mathbf{6})\end{array}$ & $\begin{array}{c}\text { Transient HypoPT } \\
\text { or normocalcaemia (n = 68) }\end{array}$ \\
\hline $\begin{array}{l}\text { Serum PTH one year } \\
\text { postoperatively }\end{array}$ & 17.02 & 32.00 & 39.75 \\
$(13.34 ; 25.25)^{\mathrm{a}}$ & $(25.75 ; 40.50)$ & $(29.75 ; 50.25)^{\mathrm{a}}$ \\
\hline
\end{tabular}

Data are given in median $(01 ; 03)$. Kruskal-Wallis test with Dunn's post-hoc test. ${ }^{a}$ Difference statistically significant in post-hoc Dunn's test $\left({ }^{a} p<0.001\right)$; ${ }^{*} p<0.05$ 
postoperative hypocalcaemia was justified by blood dilution caused by a rise in the secretion of antidiuretic hormone as well as fluid therapy in the early postoperative period and by the fact that a higher serum calcium concentration is rarely accompanied by serious symptoms. The ESE has defined hypocalcaemia as an ionised or albumin-adjusted serum calcium concentration below the normal laboratory range [7].

In the past, a dilemma regarding whether hypocalcaemia or abnormally low serum PTH should be considered a diagnostic feature of postoperative HypoPT was often solved in favour of serum PTH. In 2011, Promberger et al. described a group of eight patients with symptomatic hypocalcaemia and a normal serum PTH concentration at both 6 and 12 months after thyroidectomy [20]. The authors suggested a diagnosis of permanent relative HypoPT, noting that the patients' serum PTH concentrations were significantly lower than they had been prior to their operations. This was also the case in our study. The serum PTH concentration did not reach the normal range in two of 12 patients with hypocalcaemia at one year postoperatively. In 10 other patients, although apparently normal, their serum PTH concentrations were insufficient to maintain normocalcaemia, and they were significantly lower than they had been prior to their operations. Hungry bone syndrome, hypercalcitoninaemia, hypomagnesemia, and/or vitamin D deficiency were not found in our patients.

Lorente-Poch et al. classified permanent HypoPT into three categories: (1) aparathyroidism with undetectable PTH, (2) HypoPT with a serum PTH concentration below the normal range, and (3) relative parathyroid insufficiency, corresponding to a serum PTH concentration that is in the normal range but is insufficient for serum calcium normalisation [10]. Raffaelli et al. later extended this classification in cases of early postsurgical hypocalcaemia [21]. Recognition of patients with hypocalcaemia and an apparently normal PTH concentration as hypoparathyroid will increase the reported prevalence of postoperative HypoPT.

We found that an undetectable serum PTH concentration on POD1 is an important risk factor of permanent HypoPT. No patient with a measurable POD1 PTH concentration required treatment for hypocalcaemia one year postoperatively. Our observation was in line with previous findings of other authors. For example, in eight patients described by Promberger et al. the serum PTH concentration dropped to $1 \pm 0.8 \mathrm{pg} / \mathrm{mL}$ three hours postoperatively [20]. In a study on the factors related to the development of permanent HypoPT after total thyroidectomy in patients with Graves' disease, Hammerstad et al. reported permanent hypoparathyroidism in four of 11 patients with an undetectable serum PTH concentration 6-48 hours postoperatively and no cases of permanent hypocalcaemia in patients with a measurable serum PTH concentration [22]. In addition, Canu et al., in a retrospective study on permanent HypoPT, which they defined as a subnormal serum PTH concentration for more than 12 months after thyroidectomy, found that it occurred only in patients with an undetectable serum PTH concentration on POD1 [23].

Ten of 12 of our patients with permanent HypoPT suffered from relative parathyroid insufficiency, according to the classification proposed by Lorente-Poch et al. However, their serum PTH concentrations were significantly lower than they had been before the operation, and there were no perceivable reasons for an increased calcium requirement, meaning that parathyroid insufficiency in those patients should be considered absolute rather than relative. Therefore, we propose the term "functional" instead of "relative" for parathyroid insufficiency that presents as hypocalcaemia with a normal serum PTH concentration.

In patients who were operated on for Graves' disease, Hammerstad et al. observed that permanent HypoPT was associated with a significantly lower preoperative serum calcium concentration than for transient hypocalcaemia [22]. We did not confirm this observation in patients with papillary thyroid carcinoma, but hyperthyroidism was an exclusion criterion in our study.

Genser et al. reported that in patients with permanent HypoPT the serum calcium concentration on POD1 was significantly lower than it was in patients who did not require permanent treatment for hypocalcaemia [24]. Notably, the serum PTH was not measured in that study. In our study the POD1 serum calcium concentration in patients with permanent HypoPT was significantly lower than it was in patients with measurable POD1 PTH. It was also lower than in patients with undetectable POD1 PTH, who later recovered from hypocalcaemia, but the difference did not reach statistical significance.

Garrahy et al. found that hypomagnesaemia on POD1 was predictive of permanent hypocalcaemia in patients after total thyroidectomy [25]. Hammerstad et al. found a significant reduction in serum magnesium on POD2 in patients with permanent HypoPT compared to those with transient hypocalcaemia [22]. In the early postoperative period, a decrease in serum magnesium is secondary to that of serum PTH. In our study, both the serum magnesium concentration and the incidence of hypomagnesaemia on POD1 or serum magnesium concentration on POD2 did not allow the identification of patients at particular risk of permanent HypoPT among patients with undetectable POD1 PTH. 
Stiges-Serra et al. found that a higher serum calcium concentration one month postoperatively was the best biochemical predictor of recovery form protracted $\mathrm{Hy}$ poPT [9]. In our study all patients with undetectable POD1 PTH required treatment for hypocalcaemia one month postoperatively, which corresponded to the definition of protracted HypoPT. In patients who later recovered from HypoPT, the serum calcium concentration was higher than it was in those who developed permanent HypoPT and equal to that of patients with detectable POD1 PTH; however, the difference was less pronounced than that reported by Stiges-Serra et al., and it did not reach the threshold of significance.

The hypothesis was formulated that a higher serum calcium concentration one month postoperatively promotes regeneration of the parathyroid glands. Should it be accurate, the mitigation of permanent HypoPT would not lie solely in the hands of surgeons. However all patients in our study were treated according to the same principle of keeping the serum calcium concentration at the lower edge of the normal range; therefore, we cannot exclude that the observation regarding better chances of recovery from HypoPT in patients with a higher serum calcium concentration may reflect a better regenerative potential of the parathyroid glands that underwent a reversible ischaemia of short duration.

The number of parathyroid glands that are identified intraoperatively and left in situ is considered paramount to preventing postoperative hypoparathyroidism [26, 27]. Two intact parathyroid glands should suffice to prevent permanent hypoparathyroidism [26]. Intraoperative autotransplantation of the parathyroid glands into sternocleidomastoid muscle is advocated in cases of their removal or irreversible ischaemia; however, the role of autotransplantation in the prevention of permanent HypoPT has recently been questioned $[8,9,27]$. A few authors have observed permanent hypocalcaemia in patients with two or more parathyroid glands left in situ [20,22]. In addition, it has been proven that, in cases of permanent HypoPT, all parathyroid glands suffer irreversible vascular or thermal damage without the surgeon knowing about it [12, 20, 28]. The surgeon's ability to assess the risk for the parathyroids may have a substantial impact on the complication rates [29]. Advances in the parathyroid glands' intraoperative visualisation as well as the modification of guidelines for thyroid cancer management may help diminish the rate of this serious complication $[12,30]$.

We have addressed an important medical issue that is currently underrepresented in the medical literature. The organisation of our department, with specialists in surgery, endocrinology, and nuclear medicine working together, allows for comprehensive medical care. The prospective nature of this study and the selection of a homogenous group of patients allowed us to avoid bias, but it resulted in a small number of analysed subgroups. While this study was not innovative in its approach, the results have a solid foundation for interventional and focused studies on postoperative HypoPT.

\section{Conclusions}

An undetectable serum PTH concentration on POD1 constituted an important risk factor of permanent HypoPT, while a detectable PTH concentration has always been associated with full recovery of parathyroid glands function. In patients with permanent HypoPT the serum calcium concentrations on POD1 and one month postoperatively were lower than in patients who regained normocalcaemia; however, the differences did not reach statistical significance, which might have been related to the small sizes of the subgroups of patients. Further clinical experience tells us that patients who recovered from HypoPT despite an undetectable POD1 PTH concentration should be monitored for hypocalcaemia in situations of increased calcium demand (i.e. related to pregnancy, breastfeeding, or medication) because they may require reimplantation of the treatment.

\section{References}

1. Brown EM. Control of parathyroid hormone secretion by its key physiological regulators. In: Bilezikian JP, Marcus R, Levine M, Marcocci C, Silverberg SJ, Potts J. ed. The parathyroids: basic and clinical concepts. Third Ed. Elsevier Inc., London 2015 : 101-118.

2. Bilezikian JP, Khan A, Potts JT, et al. Hypoparathyroidism in the adult: epidemiology, diagnosis, pathophysiology, target-organ involvement, treatment, and challenges for future research. J Bone Miner Res. 2011; 26(10): 2317-2337, doi: 10.1002/jbmr.483, indexed in Pubmed: 21812031.

3. Mitchell DM, Regan S, Cooley MR, et al. Long-term follow-up of patients with hypoparathyroidism. J Clin Endocrinol Metab. 2012; 97(12): 4507-4514, doi: 10.1210/jc.2012-1808, indexed in Pubmed: 23043192.

4. Silva BC, Costa AG, Cusano NE, et al. Catabolic and anabolic actions of parathyroid hormone on the skeleton. J Endocrinol Invest. 2011; 34(10): 801-810, doi: 10.3275/7925, indexed in Pubmed: 21946081.

5. Underbjerg L, Sikjaer T, Mosekilde L, et al. Postsurgical hypoparathyroidism--risk of fractures, psychiatric diseases, cancer, cataract, and infections. J Bone Miner Res. 2014; 29(11): 2504-2510, doi: 10.1002/jbmr.2273, indexed in Pubmed: 24806578.

6. Sikjaer T, Moser E, Rolighed L, et al. Concurrent Hypoparathyroidism Is Associated With Impaired Physical Function and Quality of Life in Hypothyroidism. J Bone Miner Res. 2016; 31(7): 1440-1448, doi: 10.1002/jbmr.2812, indexed in Pubmed: 26865527.

7. Bollerslev J, Rejnmark L, Marcocci C, et al. European Society of Endocrinology. European Society of Endocrinology Clinical Guideline: Treatment of chronic hypoparathyroidism in adults. Eur I Endocrinol. 2015; 173(2): G1-20, doi: 10.1530/EJE-15-0628, indexed in Pubmed: 26160136.

8. Stack BC, Bimston DN, Bodenner DL, et al. American Association of Clinical Endocrinologists and American College of Endocrinology disease state clinical review: postoperative hypoparathyroidism - definitions and management. Endocr Pract. 2015; 21(6): 674-685, doi: 10.4158/EP14462.DSC, indexed in Pubmed: 26135962.

9. Sitges-Serra A, Ruiz S, Girvent M, et al. Outcome of protracted hypoparathyroidism after total thyroidectomy. Br J Surg. 2010; 97(11): 1687-1695, doi: 10.1002/bjs.7219, indexed in Pubmed: 20730856.

10. Lorente-Poch L, Sancho JJ, Muñoz-Nova JL, et al. Defining the syndromes of parathyroid failure after total thyroidectomy. Gland Surg. 2015; 4(1): 82-90, doi: 10.3978/j.issn.2227-684X.2014.12.04, indexed in Pubmed: 25713783. 
11. Glinoer D, Andry G, Chantrain G, et al. Clinical aspects of early and late hypocalcaemia afterthyroid surgery. Eur J Surg Oncol. 2000; 26(6) 571-577, doi: 10.1053/ejso.2000.0949, indexed in Pubmed: 11034808.

12. Giordano D, Valcavi R, Thompson GB, et al. Complications of central neck dissection in patients with papillary thyroid carcinoma: results of a study on 1087 patients and review of the literature. Thyroid. 2012 22(9): 911-917, doi: 10.1089/thy.2012.0011, indexed in Pubmed: 22827494

13. Shoback DM, Bilezikian JP, Costa AG, et al. Presentation of Hypoparathyroidism: Etiologies and Clinical Features. J Clin Endocrinol Metab. 2016; 101(6): 2300-2312, doi: 10.1210/jc.2015-3909, indexed in Pubmed: 26943721.

14. Clarke BL, Brown EM, Collins MT, et al. Epidemiology and Diagnosis of Hypoparathyroidism. J Clin Endocrinol Metab. 2016; 101(6): 2284-2299, doi: 10.1210/jc.2015-3908, indexed in Pubmed: 26943720.

15. Edafe O, Antakia R, Laskar N, et al. Systematic review and meta-analysis of predictors of post-thyroidectomy hypocalcaemia. Br J Surg. 2014; 101(4): 307-320, doi: 10.1002/bjs.9384, indexed in Pubmed: 24402815.

16. Grodski S, Serpell J. Evidence for the role of perioperative PTH measurement after total thyroidectomy as a predictor of hypocalcemia. World J Surg. 2008; 32(7): 1367-1373, doi: 10.1007/s00268-008-9545-5, indexed in Pubmed: 18340480

17. Antakia R, Edafe O, Uttley L, et al. Effectiveness of Preventative and Other Surgical Measures on Hypocalcemia Following Bilateral Thyroid Surgery: A Systematic Review and Meta-Analysis. Thyroid. 2015; 25(1): 95-106, doi: 10.1089/thy.2014.0101.

18. Puzziello A, Gervasi R, Orlando G, et al. Hypocalcaemia after total thyroidectomy: could intact parathyroid hormone be a predictive factor for transient postoperative hypocalcemia? Surgery. 2015; 157(2): 344-348, doi: 10.1016/j.surg.2014.09.004, indexed in Pubmed: 25616948.

19. Kim JHo, Chung MKi, Son YI. Reliable early prediction for different types of post-thyroidectomy hypocalcemia. Clin Exp Otorhinolaryngol. 2011; 4(2): 95-100, doi: 10.3342/ceo.2011.4.2.95, indexed in Pubmed: 21716957.

20. Promberger R, Ott J, Kober F, et al. Kinetics of serum parathyroid hormone during and after thyroid surgery. Br J Surg. 2008; 95(12): 1480-1487, doi: 10.1002/bjs.6410, indexed in Pubmed: 18991283.

21. Raffaelli M, De Crea C, D'Amato G, et al. Post-thyroidectomy hypocalcemia is related to parathyroid dysfunction even in patients with normal parathyroid hormone concentrations early after surgery.
Surgery. 2016; 159(1): 78-84, doi: 10.1016/j.surg.2015.07.038, indexed in Pubmed: 26456131

22. Hammerstad SS, Norheim I, Paulsen T, et al. Excessive decrease in serum magnesium after total thyroidectomy for Graves' disease is related to development of permanent hypocalcemia. World J Surg. 2013; 37(2): 369-375, doi: 10.1007/s00268-012-1843-2, indexed in Pubmed: 23188529.

23. Canu GL Medas F, Longheu A et al. Correlation between iPTH Levels on the First Postoperative Day After Total Thyroidectomy and Permanent Hypoparathyroidism: Our Experience. Open Med (Wars). 2019; 14: 437-442, doi: 10.1515/med-2019-0047, indexed in Pubmed: 31231683

24. Genser L, Trésallet C, Godiris-Petit G, et al. Randomized controlled trial of alfacalcidol supplementation for the reduction of hypocalcemia after total thyroidectomy. Am J Surg. 2014; 207(1): 39-45, doi: 10.1016/j. amjsurg.2013.05.007, indexed in Pubmed: 24119718.

25. Garrahy A, Murphy MS, Sheahan P. Impact of postoperative magnesium levels on early hypocalcemia and permanent hypoparathyroidism after thyroidectomy. Head Neck. 2016; 38(4): 613-619, doi: 10.1002/hed.23937, indexed in Pubmed: 25491348.

26. Thomusch O, Machens A, Sekulla C, et al. The impact of surgical technique on postoperative hypoparathyroidism in bilateral thyroid surgery: a multivariate analysis of 5846 consecutive patients. Surgery. 2003; 133(2): 180-185, doi: 10.1067/msy.2003.61, indexed in Pubmed: 12605179.

27. Lorente-Poch L, Sancho JJ, Ruiz S, et al. Importance of in situ preservation of parathyroid glands during total thyroidectomy. Br J Surg. 2015 102(4): 359-367, doi: 10.1002/bjs.9676, indexed in Pubmed: 25605285.

28. Hermann M, Ott J, Promberger R, et al. Kinetics of serum parathyroid hormone during and after thyroid surgery. Br J Surg. 2008; 95(12): 1480-1487, doi: 10.1002/bjs.6410, indexed in Pubmed: 18991283.

29. Promberger R, Ott J, Bures C, et al. Can a surgeon predict the risk of postoperative hypoparathyroidism during thyroid surgery? A prospective study on self-assessment by experts. Am J Surg. 2014; 208(1): 13-20, doi: 10.1016/j.amjsurg.2013.11.007, indexed in Pubmed: 24746378.

30. Vidal Fortuny I, Sadowski SM, Belfontali V, et al. Randomized clinical trial of intraoperative parathyroid gland angiography with indocyanine green fluorescence predicting parathyroid function after thyroid surgery. Br J Surg. 2018; 105(4): 350-357, doi: 10.1002/bjs.10783, indexed in Pubmed: 29405252 